\title{
Correction to: On fusing the latent deep CNN feature for image classification
}

\author{
Xueliang Liu ${ }^{1} \cdot$ Rongjie Zhang ${ }^{1} \cdot$ Zhijun Meng $^{2} \cdot$ Richang Hong $^{1} \cdot$ Guangcan Liu $^{3}$ \\ Published online: 27 October 2018 \\ (C) Springer Science+Business Media, LLC, part of Springer Nature 2018
}

\section{Correction to: World Wide Web (2018) \\ https://doi.org/10.1007/s11280-018-0600-3}

The original version of this article unfortunately contained a mistake. The spelling of Guangcan Liu's name was incorrect.

The original article has been corrected.

The online version of the original article can be found at https://doi.org/10.1007/s11280-018-0600-3

\section{Zhijun Meng \\ mzj.beihang@gmail.com}

1 Hefei University of Technology, Hefei, China

2 Beihang University, Beijing, China

3 Nanjing University of Information Science and Technology, Nanjing, China 